\title{
Variations in skull base morphology during phylogenesis and different hypotheses
}

\author{
F. de Brondeau
}

University Lecturer - Hospital Specialist Practitioner - University of Bordeaux

ABSTRACT

The relationships between the craniofacial structures at the base of the skull are modified during ontogenesis and phylogenesis. The scientific community is in agreement regarding the major role that the skull base has in the hominization and the etiopathology of maxillofacial dysmorphia.

Comparing ancient fossils to current populations, the origin and interpretations of the various skull base morphologies, more specifically the sphenoidal angle, are complicated. Therefore, different hypotheses are advanced. Most compare them to the larger characteristics of human evolution. In this article, they are presented as to how each author developed their respective hypotheses.

The knowledge of these hypotheses helps in the comprehension of the evolutionary mechanisms of basal craniofacial configurations of modern man.

\section{KEYWORDS}

Skull base, phylogenesis, variation

\section{INTRODUCTION}

The skull base figure is the major element in the context of hominization. During ontogeny and phylogeny, basal craniofacial relations are modified. In modern humans, the origin of these changes, both at the skull base and facial levels, remain unclear. The scientific community agrees on the major role of the skull base in hominization, and on the etiopathogenesis of maxillofacial dysmorphia.

The skull base reflects determinism (it is derived from endochordal precursors whose shapes are known to be dependent on genetic factors); it constitutes the first part of the skeleton to reach maturity (Moore and Lavelle ${ }^{46}$ ) and it finally plays an important role in shaping the face. Lieberman et al. ${ }^{41}$ demonstrate the existence of multiple, complex interactions between the skull base, the brain, and the face, and emphasize the difficulty of knowing the ontogenetic mechanisms that govern skull base flexion and its relationship to the face. Penin et al. ${ }^{52}$, Jeferry ${ }^{33}$, Bastir et al. ${ }^{5}$ stress the importance of the rhythm and timing of growth in different parts of the skull base and its connection

Address for correspondence:

François de Brondeau - UFR des sciences odontologiques

Université de Bordeaux - 16 cours de la Marne

33082 Bordeaux Cedex

E-mail: fdb33@aol.com

Article received: $10-10-2014$. Accepted for publication: 08-09-2014.

This is an Open Access article distributed under the terms of the Creative Commons Attribution License (http://creativecommons.org/licenses/by/4.0), which permits unrestricted use, distribution, and reproduction in any medium, provided the original work is properly cited. 
arrangements with the face. Thus, facial growth is dependent on genetic, epigenetic, and functional factors.

The interactions that lead to the current concept of the role of the skull base on facial morphology remain subject to much controversy.

Because of its embryogenesis and ontogenesis, the skull base appears as a true "pivot" (Hoyte ${ }^{32}$ ) on which the sphenoid bone occupies a central position. The latter, in various craniometric and cephalometric studies, presents correlations with the anteroposterior facial skeletal discrepancy.

In anthropology, these mechanisms between skull base and facial morphology, as well as the implementation method of a specific architecture for each population, remain subject to numerous hypotheses.

Therefore, the interpretation of variations in skull base morphology, and more particularly in the sphenoidal angle, is difficult. Most studies not only involve major characteristics of human evolution, such as brain development, postural changes, facial verticalization, but also morphogenetic factors, such as genome mutation or the influence of soft tissues, with the fundamental role of masticatory forces.

Yet most often, these hypotheses overlap and are difficult to classify.

For analysis purposes, we will present them according to the primary factor that they each highlight chronologically, according to the authors, along with their differences.

As such, for Strait ${ }^{67}$, most hypotheses are so-called "structural" in nature, meaning that any change of the skull base skeleton during evolution is the result of an alteration in another anatomical region.

Other hypotheses are "functional," connecting all morphological variation of the skull base to a change in behavior or function. But at present, most authors agree on an interactive role among the different structural and functional factors. Indeed, skull base characteristics can be correlated with one or more structural or functional phenomena (Strait ${ }^{67}$ ).

\section{VARIATIONS IN THE EVOLUTION OF BASAL CRANIOFACIAL RELATION: PHYLOGENETIC HYPOTHESES}

\section{Brain development hypotheses}

- Hypotheses correlating the skull base shape to brain size are among the oldest. Papillaut ${ }^{51}$, Bolk ${ }^{9}$, Anthony², Beauvieux ${ }^{7}$, Ashton, and Zuckerman ${ }^{3}$ had argued that the development of the frontal and parietal lobes caused development of the skull in the three dimensions of space, followed by the rise of the skull, frontal remodeling, and its backward and downward development. This posterior coiling, whose center is located in the sella turcica region, could be the origin of the stop of the rear portion of the cerebral mass against the occipital bone and the clivus, causing the skull base flexion.

- Beauvieux ${ }^{7}$ already stressed the "hinge" role of the spheno-occipital synchondrosis, which enables the 
lowering of the basal occipital portion relative to the basal sphenoid portion.

- If the authors agree on the fundamental constraint of the brain on the shape of the skull base, the debate remains open regarding the mechanisms involved, notably the impact of brain development on the anterior portion of the skull base.

For some, it is the development of the anterior part of the frontal lobe that impacts ethmoidal evolution.

- In 1965, Olivier ${ }^{50}$ already highlighted one of the essential elements of contradiction in this encephalic hypothesis for skull base flexion. Indeed, the posterior development of the brain exists already in primates and the sphenoid angle opens, whereas in humans it is subject to ontogenetic closure.

- For Gould ${ }^{31}$, in 1966, the combination of increase in the brain's relative size and the decreased length of the skull base (spatial-packing hypothesis) would be the most important factor of skull base flexion in modern humans.

- However, Ross and Ravosa58 and Spoor ${ }^{65}$ only sustain this hypothesis for nonhuman primates.

- For Moss ${ }^{47}$, Dean $^{12}$, and Strait ${ }^{66}$, according to the aforementioned socalled spatial-packing hypothesis, a more flexed skull base is a way to increase the volume of the cerebral lodging for a given skull base length.

- The works of Ross and Henneberg ${ }^{56}$ have demonstrated that in modern man, skull base flexion and brain size relative to skull base length are not significantly correlated, but are rather related to the orientation of the face.

- For Spoor65, humanization results in skull base flexing associated with increased brain size. However, if the brain is to influence skull base morphology, the initial stage will affect skull base flexion by accentuating it.

- For Lieberman et al. ${ }^{41}$, the impact of cerebral development in modern man would occur on its width which, on a narrow skull base, would result in projection of the posterior occipital bone. In his opinion, the main factor is the greatest width of the skull base (which affects the entire neural skull base complex), which would be accompanied by narrower, longer faces in the anteroposterior dimension.

- Strait ${ }^{66}$ considers that, if skull base flexion could be an adaptation to accommodate the relative size of the brain to the length of the skull base, the reason for this adaptive phenomenon is not related to the reduction of the skull base length. In his study, Strait ${ }^{66}$ shows that the latter is inversely proportional to the development of the diencephalon, mesencephalon, and myelencephalon. He concludes that the development of these brain components could be responsible for the development of the skull base flexion.

- McCarthy ${ }^{45}$ was interested in these cephalic hypotheses, which were based on two studies (Ross and Henneberg ${ }^{56}$, Spoor $\left.{ }^{65}\right)$. Both studies agreed on the fact that the skull base flexion degree is linked to the relative volume of the brain and the length of the skull base.

- Thus, Spoor65 contradicts the arguments of Ross and Henneberg ${ }^{56}$ using different references: the cephalization index reflects the ethmoidal lamina cribrosa. The results show that among Homo sapiens, the skull base is no less flexed than expected for a primate with respect to the relative size of the brain. 
McCarthy ${ }^{45}$ insists on the difference in the hypotheses of Ross and Henneberg ${ }^{56}$ and Spoor ${ }^{65}$, whose interest is to raise the question of the origin of the highest skull base flexion in modern humans: is it related exclusively to a large brain or does it result from other factors such as posture or pharyngeal morphology?

The results of the study by McCarthy ${ }^{45}$ indicate that the posterior part of the skull base and sphenoidal plane are significantly shorter in Homo sapiens than in apes, as a result of a greater cephalic index.

Therefore, measurements of the skull base flexion and the relative size of the brain allow quantifying skull base architecture in Homo sapiens and apes.

- Jeffery ${ }^{33}$, in a comparative study of intrauterine skull base growth in nonhuman primates, questions the spatial-packing hypothesis.

- The work of Ross et al. ${ }^{57}$ emphasizes that skull base flexion may be the consequence of the relative increase of brain size, but other factors might influence flexion during postnatal growth as suggested by Jeffery and Spoor ${ }^{35}$.

\section{Postural hypotheses}

- Weidenreich ${ }^{71}$, Schultz $^{59}$, Dubrul $^{27}$ have already demonstrated over the first half of the 20th century the role of posture on skull base configuration. In fact, the skull base, because of its continuity with the vertebral column, is the site of its union with the cephalic skeleton. Thus, the transition to the standing position is accompanied by a ventral "rotation" of the posterior region of the skull base.
- Delattre and Fenart ${ }^{19}$ took up the study of mechanical factors (especially standing upright) that changed skull base morphology. They have attempted to link the changes in shape observed in terms of the forces acting on the cephalic region.

For them, the anterior region of the skull base, during body remodeling, either remains fixed or is subject to proportional development. Posture verticalization thus acts only upon the posterior region, causing the displacement of the sphenoid clivus and therefore of the posterior portion of the base toward the front, thereby increasing skull base flexion in the sella turcica area.

This flexion of the skull base allows the development of the brain. As Beauvvieux ${ }^{7}$, Delattre and Fenart ${ }^{19}$ were able to demonstrate by using the vestibular referential, the essential basis of postural hypothesis is not the plane fixity in relation to the clivus displaced by the standing position, but the skull base flexion that allows the secondary development of the brain.

Although several paleontologists agree with this design showing that the standing position appears before cephalization, discussion of this hypothesis remains valid.

- Bolk ${ }^{9}$, since 1926, supports a postural hypothesis regarding the central development, but does not describe it in the same way. He opposes the theory presented above by showing that at the ontogenic level, skull base flexion exists in the fetuses of primates and all mammals, and therefore cannot be caused by the standing posture. 
The standing position is not the cause but instead the consequence of the sphenoid angulation, or more precisely, of the persistence of this angle. The foramen magnum's anterior position is not related to standing position, because it precedes the latter. The vertical remodeling would not be the cause, but rather the consequence, and would prevent the foramen from receding.

It is interesting to note that, to support this notion, Bolk ${ }^{9}$ advances embryological data: the persistence of fetal characters and the slow development of human fetuses. Thus, during ontogenesis in primates, a common position of the foramen magnum is observed in the fetus, but it is displaced backward, in contrast to what is observed in humans.

- Ashton and Zuckerman ${ }^{3}$, Adams and Moore $^{1}$, and Dean and Wood ${ }^{14}$ agree with the previous concept. For them, the skull base flexion is an adaptation to the foramen magnum's anterior rotation, which reorients itself ventrally, so as to place the occipital condyles below the head's center of gravity.

- Leroi-Gourhan ${ }^{39}$ suggests that the change in posture is probably the main factor responsible for the morphogenetic development of the craniofacial skeleton, but also emphasizes the importance of the forces developed by mastication, which would play a vital role in the balance of the cephalic pole.

- The work of Ross and Ravosa ${ }^{58}$ supports the postural hypothesis, by showing that standing primates feature more flexed skull bases than other primates. However, since then, Strait and Ross ${ }^{68}$ have shown that the study by Ross and Ravosa was missing data and did not enable such a conclusion. In contrast, Strait and Ross $^{68}$ assumed as hypothesis basis that, in order to move from a quadruped primate species to a bipedal species, it was necessary to the field of vision, which secondarily leads to skull base flexion.

The study Strait and Ross is important because it shows that, if the postural hypothesis is confirmed, the postures of the head and neck are not the primary determining factors of flexion.

- According to Spoor ${ }^{65}$, who favors the brain development hypothesis, the postural hypothesis can be retained to understand skull base flexion in hominids. In fact, he was able to find more flexed bases in some species, which should not have led to the relative size of their brains.

- More recently, the study of McCarthy ${ }^{45}$ has taken up the steps of the spatial-packing hypothesis. However, the results lead to support the influence of bipedal posture and pharyngeal dimensions on skull base morphology.

Indeed, one of the most interesting findings of McCarthy ${ }^{45}$ is that the posterior part of the skull base and the sphenoid plane are significantly shorter in Homo sapiens than in apes. This ties to the hypotheses by Dean ${ }^{12}$, whereby the vertical remodeling and biped posture of Homo sapiens require a shorter posterior portion of the skull base and a smaller pre-pituitary region of the sphenoid bone than in other apes. 


\section{Facial bone development hypotheses}

These hypotheses are among the oldest, and rest upon ontogenic data: in the fetus, the face is smaller and the sphenoidal angle is closed; thereafter, the face develops, resulting in the opening of the sphenoidal angle followed by the projection of foramen magnum toward the rear or ascension of the sphenoidal plane.

Looking at growth in humans, the morphogenesis data is confirmed, as there is a decrease in the sphenoid angle up to the prepubertal period, and eventually increase again along with the development of the face.

In primates, a correlation between the facial angle and the sphenoid angle is found among the different species, resulting in an opening of the skull base angle with closing of the facial angle. It is the development of the face that causes such phenomenon.

- Another factor advanced by advocates of these hypotheses is that the face and skull base share several ossification centers. Thus, an alteration in the architecture of the face may be followed by skull base change.

But as Strait ${ }^{67}$ points out, although many studies have examined the relationship of the face and skull base flexion (Dabelow ${ }^{11}$; Scott ${ }^{60}$; Enlow ${ }^{29,30}$; RossetRavosa58), the ensuing facial rotation hypotheses remain questionable.

The measurement method described in these studies is in itself a major problem. In fact, the orientation of the face is most often appraised by studying the angle between the palatal plane and the skull base. It is therefore normal to find correlations between skull base characteristics and facial orientation. For Strait ${ }^{67}$, it is necessary to measure the facial prognathism using a referential that involves no connection with certain features of the skull base.

- Dean and Wood ${ }^{13}$, in inquiring about the similarity in the width and length of the skull base morphology in Australopithecus robustus and Homo sapiens sapiens, have shown that different facial mechanisms entail the same transformations at the skull base. Their study shows that the rotation of the face below the wide neurocranium in modern man, and the orthognathic face with wide jaws of Australopithecus robustus, would have the same implications at the skull base level: a reduction in the sphenoid body and angle.

- Lieberman ${ }^{40}$, in an assay of human fossil radiographs, has shown that the skull base flexion angle is greater on average by $15^{\circ}$ in the archaic Homo sapiens lineage than in hominids from the Pleistocene and in modern man.

He concludes that this difference, which results in the closure of the sphenoid angle in modern humans, is related to facial retraction and other factors such as the smaller pharynx behind the palate.

\section{Functional or muscle hypotheses}

\section{The influence of masticatory forces}

- Papillaut ${ }^{51}$ already evoked the influence of masticatory forces, and more particularly, of the pterygoid strap on skull base flexion. For him, important masticatory forces, or more exactly the stress generated 
by the pterygoid strap, entail sphenoid angle closure.

- Sicher ${ }^{61}$, Dubrul28, and Spencer ${ }^{64}$ have identified numerous masticatory variables that may influence skull base characteristics. It would appear from Strait ${ }^{67}$ that the most significant area is the glenoid fossa, whose relative position to the occlusal plane can change the amplitude of occlusal forces and the effectiveness of the masticatory muscles. In contrast, for Ross and Ravosa ${ }^{58}$, the deeper, more pronounced glenoid fossa in anatomically modern man, with a less developed posterior apophysis, would be the consequence of skull base flexion.

The question is whether it is the masticatory forces which, in leading to skull base closure, have changed the configuration of the glenoid fossa, if the cause-effect action is reversed. for Radinsky ${ }^{53}$ and Demes ${ }^{20,21}$, skull base flexion can play a role in resisting the constraints imposed by mastication.

Varrela ${ }^{69}$, in a comparative study between a population with a solid-based diet to a population with a more liquid-based diet shows no significant differences in the sphenoid angle.

\section{Influence of ventilation and language}

- Scott ${ }^{60}$ hypothesized a connection between the skull base and regression of cones during development, itself linked to better skin temperature regulation.

Thus, would the "remote cause" of skull base flexion be linked to an adaptation of the skin?

- Laitman et al. ${ }^{36,37}$, in a study of fossil hominids showed that the skull base could be an indicator of their respiratory system, noting the existence of relations between the exocranial orientation of the skull base and the position of upper respiratory structures. Thus, the effect produced by the descent of the tongue and larynx can be one of the factors responsible for the change in inclination of basal occipital position and the flexion, by changing the inserts of the constrictor muscle system of the pharynx.

- For Lieberman et al. ${ }^{43}$ and Dean and Wood $^{14}$, skull base flexion increase can be linked to a shift in the basal occipital position and attachment of different ligaments and suprahyoid muscles.

- Laitman et al. ${ }^{36}$ have suggested that significant decreases in the size of the nasopharynx and oropharynx and the oral cavity lead to the skull base flexion.

According to Lieberman et al. ${ }^{43}$, the combination of an anteroposteriorly short oral cavity and oropharynx, and a situation of low pharynx, enabled the expression of speech.

- Washburn ${ }^{70}$ stressed the role of brain functions, and in particular the acquisition of language, in the expansion of the brain and the cephalic evolution of man.

- Strait ${ }^{67}$ stresses that it is difficult, at present, to test the hypotheses linking the shape of the skull base and speech (Lieberman et al. ${ }^{43}$; Reidenberg and Laitman ${ }^{54}$ ), because of the methodological difficulty in evaluating speech.

- Jeffery ${ }^{34}$, following an ontogenetic study of human fetuses, questions the hypothetical link between the 
formation of the upper airways and skull base flexion phenomena during intrauterine life.

\section{Multifactorial hypotheses}

\section{Integration hypothesis}

Based on the fact that many variables influence the skull base and considering the key role of the latter in craniofacial architecture as a whole, Lieberman et al. ${ }^{42}$ speculate that these so-called variables can affect other aspects of the cranial shape via the skull base structure.

Therefore, they raise the issue of the role of the skull base in craniofacial development and evolution through its integration.

This notion of craniofacial integration was defined by Smith" ${ }^{63}$ as "the combination of elements through the play or regrouping of mechanisms, explaining that any change in one element is accompanied by changes in the other."

But for Cheverud ${ }^{10}$, integration is defined as "a process referring to the connections and interactions between morphological elements."

The skull base is described as acting directly through the development and function with variations affecting the skeleton, muscles, neurosensory complex, and particularly the brain, the orbits, the ethmoidal complex, and the cervical spine. All these units have direct or indirect actions on other potential units such as the oropharynx and the nasopharynx, the mandible, and the dental arches (Lieberman ${ }^{40}$ ).

But does the skull base play an active or passive role in the integration of the cranial shape among these units, and how?
Lieberman ${ }^{40}$ suggests that the skull base may partially play an "intermediary role" during growth between the brain and the face and between the craniofacial complex and the neck. It relies on anatomic and physiological considerations, because skull base appears to be the common boundary of different regions. However, a question remains: given the complexity of the relational mechanism, what are the current units in the skull base and facial skeleton that interact, and what are their regulatory mechanisms?

- For Moss ${ }^{48}$, this integration phenomenon can occur through direct induction or mechanical interactions of the neighboring bone tissue. In fact, the side effects of growth cause changes in the management of relations between the bones in different anatomical regions. According to $\mathrm{Moss}^{48}$, it is either the action of a single gene that would affect multiple regions, or the coordination of several genes by pleiotropy. The genetic hypothesis is advanced herein. Deshayes ${ }^{26}$ evokes the Hox system genes as the mechanism underlying the flexion of the skull base.

- This integration concept was echoed by Lieberman et al. ${ }^{42}$ in a study of the skull base in primate showing strong relationship percentages between skull base shape variations and factors such as brain volume, skull base length, facial angle, and posture. In humans, the skull base angle is related to the length, width, and brain size.

The results indicate a "pattern" by which multiple combined factors influence the flexion angle, so that a variability in the angle itself may play multiple roles in modulating the interactions among the various cranial regions. 
But this, as highlighted by these authors, remains to be tested more accurately. This is also why the same authors are currently seeking to identify a cellular determinism through histological examinations for explaining the interaction mechanisms to better understand the integration.

- Strait ${ }^{67}$, in order to explain the functional and structural relationships of the skull base characters, offers a hypothesis according which phylogenetic independence cannot be demonstrated, because these characters are presumed integrated and bundled in a complex. But his study shows that the concept of integration can only be used in a phylogenetic analysis if the integration hypotheses can be tested properly.

- Penin et al. ${ }^{52}$, using Proscrutes superimpositions comparing growth paths in modern humans and chimpanzees, argue that the human brain is the result of a simple change in growth allometry by gene regulation. For these authors, the structural features such as the skull base flexion and the face of modern man are more closely related to masticatory, respiratory, and locomotive phenomena.

- Bastir and Roses ${ }^{4}$, based on a sample of modern men ( $n=144)$, suggest the hypothesis of a "petromandibular" unit which would be the consequence of changes in the phylogenetic skull base configuration and in posterior face during hominization. Their study shows that in modern man, this morphological integration is organized hierarchically.

- Simonis-Sweat62, through the work on geometric morphometrics on craniofacial variability in a sample of 290 current and fossil subjects, shows that skull base flexion results from allometric relationships as well as static growth. His analysis shows that the face, the vault, and the skull base function as three semiautonomous modules. According to the authors, the integrated structure of the skull would result from allometric and geometric constraints.

In contrast, cranial configuration variations are interpreted by interactions over the effect of muscle growth on bone structures.

\section{Delaire Hypothesis 15-18}

According to Delaire, skull base development is essentially under the influence of three fundamental factors: head formation, mastication, and brain expansion.

- He highlights the key role of soft tissue in cephalic skeletal changes during phylogeny. Muscles and viscera would act first on the pre-skeletal mesenchyme, then on skeletal parts derived therefrom. To support this hypothesis, he analyzed the different factors of cephalic morphogenesis and their action mechanisms (Delaire $\left.{ }^{16}\right)$.

Thus, over phylogeny, head and neck muscles, especially the posterolateral cervical muscles (mainly responsible for head remodeling during ontogeny) played the main role in the rotation of the back of the skull, in skull base flexion, and in the changes in the remainder of the cranial vault. Moreover, relying on the work of Björk ${ }^{8}$, Riolo et al. ${ }^{55}$, he points out that after the acquisition of the upright posture, the angle of the skull base of children and adolescents changes in normal physiological conditions, while the head continues 
to grow. The closure of the sphenoid angle would therefore depend more on brain development than on head remodeling.

He also recalled that in hominids, the adoption of the upright posture and "cephalic humanization" preceded the growth of the brain.

- The action of the superficial and deep facial muscles in the human phylogenetic lineage is mainly effective at the level of facial morphology. In ensuring the lower position of the hyoid bone and the tongue in Homo sapiens sapiens, deeper-seat dampers allow the release of the oral cavity and facilitate the retraction of the maxilla and the mandibular body. This is followed by the modification of facial relief (accentuation of the nose and chin) under the control of superficial facial muscles.

- Mastication has contributed to the development of the temporomandibular joint (TMJ) but also the evolution of all elements of the craniofacial skeleton, especially in apes and hominids (Delaire ${ }^{16}$ ).

In addition, the effects on the mandible and dentition because of the type of diet and the development of the masticatory muscles, through the change in occlusal forces, has determined the development and expansion of intraosseous pillar insertion ridges for maxillary reinforcement, which run from the vault and skull base (Delaire $\left.{ }^{16}\right)$. The impact of the masticatory muscles through occlusal forces had already been demonstrated by Leroi-Gourhan ${ }^{39}$.

In addition to this muscular action, Delaire also emphasizes the role of the brain in cephalic humanization. In fact, it has not only followed the expansion of the cranial vault triggered by head remodeling; it would also have strongly contribute through its own growth linked to the development of brain function. The latter was determined by cultural changes, language, imagination, and writing (Lieberman et al. ${ }^{43}$ ).

Conclusion: we see in this theory the complexity and interaction of several determining factors.

Thus, between the upright posture, increased brain capacity, and brain development, there are direct correlations whose effects have gradually led to Homo sapiens sapiens.

\section{Deshayes Hypothesis ${ }^{22-26}$}

This hypothesis is based on a concept of "craniofacial biodynamics," resulting in a craniofacial skeleton arrangement as part of a "three-dimensional facial contraction process resulting in the ontogenetic phenomenon of skull base flexion" (Deshayes ${ }^{26}$ ).

The Deshayes thesis is complex. To explain it, the author recalls the concept of integration that we mentioned previously in this chapter.

Deshayes ${ }^{26}$ summarizes the changes during humanization in a change in the cephalic pole toward sagittal shortening, broadening of the skull base, and an increase of vault height, resulting in the "plication" of the cranial base.

To understand the origin of this flexion phenomenon, Deshayes bases his hypothesis on the work of Moss et al. ${ }^{49}$, which demonstrates the development of skull base flexion in primates because of the overlying neural tube.

Histological studies are guided toward the same concept, namely, that over the course of ontogeny, there is a succession of neural vesicle displacements that would imprint repositioning on the 
underlying chondocranial units that would cause flexion.

For Deshayes, the synchondrosis of the skull base would limit the areas or functional units directly activated by the overlying neural vesicles. Deshayes evokes the establishment, since early neural development, of a biodynamic cell network that would organize itself from the microscopic level to the macroscopic level. This cell network would be able to integrate genetic and physiological-biochemical information. Thus, this design approaches the integration concept retaken by Lieber$\operatorname{man}^{40}$

Deshayes assumes the existence of a kinetic process within skeletal components, and raises the possibility of development to different morphologies through changes in the balance points of bone segments.

This supports his cranial biomechanics theory, according to which skull base flexion is a reflection of the kinetic forces acting on the occipital and sphenoid bones.

For Deshayes, "the study of the craniofacial contraction phenomenon must be analyzed independently of the biomechanical process that led to flexion." It results in two different tables in terms of facial typology as defined in orthodontics.

The application of this cranial biomechanics theory in paleoanthropology is complex, but for Deshayes ${ }^{26}$, if the flexion phenomenon is "a required phenomenon in primates, it is not exclusive of one biomechanical pattern." Its origin would be a different biomechanics, with different sphenoidal-occipital kinetic modes.

For Deshayes, in fact, the question of what part initiates the cephalic humanization phenomenon remains open. This cephalic kinetics would explain why the occipital rotational movement (the initiation of the cephalic hominization phenomenon for Delattre and Fénart ${ }^{19}$ ) is accompanied by sphenoid kinetics, playing a role somehow as second engine of flexion. For Deshayes, bipedalism would have strengthened the "occipital engine." Deshayes ${ }^{25,26}$ offers a summary showing the interactions between phylogenetic and morphological factors.

On the basis of the impact of the environment on bipedalism, with the data by Beals ${ }^{6}$, for whom "climatic stress" is, on the phylogenetic level, the accelerator of the skull base flexion process, Deshayes develops his cranial biodynamics hypothesis. The craniofacial system must be ready to adapt and integrate the different factors of transformation.

The origin of this transformation is histological. The work of Lengelé 38 points to the existence of "a phylogeny in calcified tissues at both the morphological and topographical levels." He notes that, as cartilaginous tissue may change phenotypic expression, it will invade part of the chondrocranium. This tissue is the common denominator in all neurocranial developmental stages, prior to intrasphenoidal synchondrosis. It will therefore play a fundamental role in the organization of this region. On the other hand, according to Deshayes, following intrasphenoidal synchondrosis, the region that builds basioccipital bone, basal sphenoid bone, and the petrous pyramids will be dependent on Hox system genes, which constitute "the first primitive engine of flexion."

Conclusion: the characteristic of the Deshayes hypothesis is to show 
the need for the establishment of biodynamics that would behave as a true interface between the genome and the environment. Thus, as the skeletal pieces grow, they change their relationship with each other, which results in a specific craniofacial configuration arrangement, which represents an integration of different factors.

\section{CONCLUSION}

This anthropological approach emphasizes the importance of the skull base and its consequences to the organization of the craniofacial complex. Knowledge of basal craniofacial development in phylogeny can help orthodontists and practitioners in understanding facial morphology, an area of care for which they are responsible.

On the basis of different hypotheses, it is currently difficult to know precisely what is the key factor or element responsible for craniofacial development.
The elements underlying the various theories are many, but one cannot help but accept their interactions as emphasized by Lieberman et al. ${ }^{41,42}$ and Strait ${ }^{67}$. Soft tissues appear to play a key role.

For most authors, the skull base is still a better source of information than any other part of the skeleton at the phylogenetic level.

Conflict of interest: The author reports no conflict of interest.

\section{BIBLIOGRAPHY}

1. Adams LM, Moore WJ. A biomechanical appraisal of some skeletal features associated with head balance and posture in the Hominoïds. Acta Anat (Basel) 1975;92:580-594.

2. Anthony J. Influence des facteurs encéphaliques sur la brisure de la base du crâne chez les primates. Ann Paléontol 1952;38:69-79.

3. Ashton EH, Zuckerman S. Age changes in the position of the occipital condyles in the chimpanzee and the gorilla. Am J Phys Anthropol 1952;10:277-288.

4. Bastir M, Rosas A. Hierarchical nature of morphologi- cal integration and modularity in the human posterior face. Am J Phys Anthropol 2005;128:26-34.

5. Bastir M, Rosas A, O'Higgins P. Craniofacial levels and the morphological maturation of the human skull. J Anat 2006;209:637-654.

6. Beals KL, Smith CL, Dodd SM. Climate and the evo- lution of brachycephalization. Am J Phys Anthropol 1983;62:425-437.

7. Beauvieux J. Essais d'une systématisation anthropolo- gique et comparative de l'architecture craniofaciale. Bull et Mém Soc Anthrop 1946;9e série,7(4-6):105-130.

8. Bjork A. Cranial base development. Am J Orthod 1955;41:198-225.

9. Bolk L. On the problem of anthrogenesis, Proc Section Sciences. Verh Akad Wet Amst 1926;29:465-475. 
10. Cheverud JM. Developmental integration and the evolution of pleiotropy. Am Zool 1996;36:44-50.

11. Dabelow A. Über Korrelationenin der phyloge- netischen Entwicklung der Schadelform. Gegenbaurs Morphol Jahrb 1929;63:1-49.

12. Dean MC. Growth processes in the cranial base of hominoids and their bearing in morphological simi- larities that exist in the cranial base of homo and paranthropus. In Evolutionary history of the robust Australopithecus. New York: FE Grine Ed, 1988:107-112.

13. Dean MC, Wood BA. Metrical analysis of the basicra- nium of extant hominoids and Australopithecus. Am J Phys Anthropol 1981;54:63-71.

14. Dean MC, Wood BA. Basicranial anatomy of Pléo- Pleistocene hominids from East and South Africa. Am J Phys Anthropol 1982;59:157-174.

15. Delaire J. Le syndrome prognathique mandibulaire. Orthod Fr 1976;47:203-218.

16. Delaire J. Évolution du complexe dento-maxillo-facial dans la phylogenèse et l'ontogenèse humaines. Traité de pathologies buccales et maxillo-faciales. The Agency. Piette, Reischler, Balk Université, 1991:17-66.

17. Delaire J. Le développement adaptatif de la base du crâne. Justification du traitement précoce des dys- morphoses de classe III. Rev Ortho Dento Faciale 2003;37:243-265.

18. Delaire J. Le concept " cortical ». Application au déve- loppement du maxillaire. International Orthodontics 2006;4:241-260.

19. Delattre A, Fenart R. L'hominisation du crâne étudiée par la Méthode vestibulaire. Paris: CNRS, 1960:418 p.

20. Demes B. Biomechanics of primates skull base. Berlin: Springer-Verlag, 1985:59 p.

21. Demes B. Fonctional interpretation of some charac- ters of fossil hominid skulls. Définition et origines de I'homme. Paris: Sakka Ed., 1986:283-291.

22. Deshayes MJ. Croissance craniofaciale et orthodon- tie. Paris: Masson, 1986:87 p.

23. Deshayes MJ. La biodynamique craniofaciale. Rev Ortho Dento Faciale 1988;22:283-298.

24. Deshayes MJ. Reconsidération de la croissance cranio- faciale au cours du développement et de l'évolution. Conséquences en orthopédie dento-maxillo-faciale. Rev Ortho Dento Faciale 1991;25:353-365.

25. Deshayes MJ. Étude dynamique et biométrique de l'architecture crânienne. Cah Anthropol Biom Hum 1961;1-2:171-189.

26. Deshayes MJ. Repérages crâniens. Bannalec: Cranexplo éd., 2000:120 p.

27. Dubrul EL. Posture, locomotion and the skull Lagomorpha. Am J Anat 1950; 87:277-313.

28. Dubrul EL. Early hominid feeding mechanisms. Am J Phys Anthropol 1977;47:305-320.

29. Enlow DH. Hand book of facial growth. Philadelphia, London, Toronto: Saunders company, 1975:423 p.

30. Enlow DH. Postnatal growth and development of the face and cranium. In: B. Cohen. Scientific foundation ofdentistery. London: IRV Kramer éd., 1976:29-46.

31. Gould SJ. Allometry and size in ontogeny and phylogeny. Biol Rev Camb Philos Soc 1966;41:587-640.

32. Hoyte DA. The cranial base in normal and abnormal growth. Neurosurg Clin North Am $1991 ; 2: 515-537$.

33. Jeffery N. Brain expansion and comparative prenatal ontogeny of the non-hominoïd primates cranial base. J Hum Evol 2003;45:263-264. 
34. Jeffery N. Cranial base angulation and growth of the human fetal pharynx. Anat Rec A Discov Mol Cell Evol Biol 2005;284A:491-499.

35. Jeffery N, Spoor CF. Brain size and the human cra- nial base: a prenatal perspective. Am J Anthropol 2002;118:324-340.

36. Laitman JT, Heimbuch RC, Crelin ES. Developmental change in a basicranial line and its relationship to the upper respiratory system in living primates. Am J Anat 1978;152:467483.

37. Laitman JT, Heimbuch RC, Crelin ES. The basicranium of fossil hominids as an indicator of their upper respira- tory systems. Am J Phys Anthropol 1979;51:15-34.

38. Lengele B. Le tissu chondroïde dans le squelette en croissance. Louvain: Université catho fac Med Unité Anat Hum, 1997:224p.

39. Leroi-Gourhan A. Mécanique vivante, Le crâne des vertébrés du poisson à I'homme. Paris: Fayard, 1983:261 p.

40. Lieberman DE. Ontogeny, homology, and phylogeny in the hominid craniofacial skeleton: the problem of the browridge. In: P. O'Higgins, M Cohn. Development, growth and evolution: implications for the study of hominid skeletal evolution. London: Academic Press, 2000:85-122.

41. Lieberman DE, Pearson OM, Mowbray KM. Basicranial influence on overall cranial shape. J Hum Evol 2000;38:291-315.

42. Lieberman DE, Ross CF, Ravosa MJ. The primate cra- nial base: Ontogeny, function and integration. Am J Phys Anthropol 2000;suppl 31:117-169.

43. Lieberman P, Crelin ES, Klatt DH. Phonetic ability and related anatomy of the new born and adult human, Neanderthal man and the chimpanzee. Am J Anthropol 1972;74:287307.

44. Lieberman P, Laitman JT, Reidenberg JS, Gannon PJ. The anatomy, physiology, acoustics and perception of speech: essential element in analysis of the evolution of human speech. J Hum Evol 1992;23:447-467.

45. Mc Carthy RC. Anthropoid cranial base architecture and scaling relationships. J Hum Evol 2001;40(1):41-66.

46. Moore WJ. Lavelle CLB. Growth of the facial skeleton in the Hominoidea. London: Academic Press, 1974:236 p.

47. Moss ML. Rotation of the cranial components in the growing rat and their experimantal alteration. Acta Anat 1958;32:65-86.

48. Moss ML. The functional matrix hypothesis revisited 1. The role of mechanotransduction. Am J Orthod Dentofacial Orthop 1997;112:8-11.

49. Moss ML, Moss-Salentijn L, Vilmann H, Newell- morris L. Neuro-skeletal topology of the primate basi- cranium: its implication for the fetalization hypothesis. Gegenbaurs Morphol. Jahrb 1982;128:58-67.

50. Olivier G. Anatomie anthropologique. Paris: Vigot, 1965:488 p.

51. Papillault G. Étude morphologique de la base du crâne. Bull et Mém Soc Anthropol de Paris 1898:336-385.

52. Penin X, Berge C, Baylac M. Ontogenic study of the skull in modern humans and the common chimpazees: neotonic hypothesis reconsidered with a tridimensional Procrustes analysis. Am J Anthropol 2002;118:50-62. 
53. Radinsky LB. A new approach to mammalian cra- nial analyses illustraded by examples of prosimian primates. J Morphol 1969;124:167-180.

54. Reidenberg JS, Laitman JT. Effect of basicranial flexion on larynx and hyoid position in rats: an experimental study of skull and soft tissue interactions. Anat Rec 1991;230:557569.

55. Riolo ML, Moyers RE, Mc Namara JA, Hunter WS. An Atlas of crânio-facial growth. Michigan: Center for Human Growth and Developpement 1974:379 p.

56. Ross CF, Henneberg M. Basicranial flexion, relative brain size and facial kyphosis in human primates. Am J Phys Anthropol 1995;98:575-593.

57. Ross CF, Henneberg M, Ravosa MJ, Richard S. Curvilinear, geometric and phylogenetic modeling of basicranial flexion: is it adaptive, is it constrained? J Hum Evol 2004;46:185213.

58. Ross CF, Ravosa MJ. Basicranial flexion, relative size and facial kyphosis in nonhuman primates. Am J Phys Anthropol 1993;91:305-325.

59. Schultz $\mathrm{AH}$. Conditions for balancing the head in primates. Am J Phys Anthropol 1942;29:483-497.

60. Scott JH. The cranial base. Am J Phys Anthropol 1958;16:319-348.

61. Sicher H. Phylogenesis of human temporomandibular articulation. J Dent Res 1937;16:339340.

62. Simonis-Sueur C. Morphométrie géométrique appli- quée à la compréhension de la variabilité craniofaciale des Homo sapiens adultes. Thèse de doctorat du Museum national d'Histoire naturelle. Paris: Museum national d'Histoire naturelle, 2006:344 p.

63. Smith KK. Integration of craniofacial structures during development in mammals. Am Zool 1996;26:70-79.

64. Spencer MA. Force production in the primates masti- catory system: electromyographic tests of biomechani- cal hypotheses. J Hum Evol 1998;34:25-54.

65. Spoor CF. Basicranial architecture and relative brain size of Sts 5 (Australopithecus Africanus) and other Plio-Pleistocene hominids. South African J of Sci 1997;93:182-187.

66. Strait DS. The scaling of basicranial flexion and length. J Hum Evol 1999;37:701-719.

67. Strait DS. Integration, phylogeny and the hominid cranial base. Am J Phys Anthropol 2001;114:273-297.

68. Strait DS, Ross CF. Kinematic date on primate head and neck posture: implications for the evolution of basicranial flexion and an evaluation of registration plabes. Am J Phys Anthropol 1999;108:205-222.

69. Varrela J. Effect of attritive diet on craniofacial morphology: cephalometric analysis of finnish skull sample. Eur J Orthod 1990;12:219-223.

70. Washburn SL. The evolution of man. Sci Am 1978;239:194-204.

71. Weidenreich F. Die Sonderform des Menschenschalds als Anpassung an den aufrechten Gang. Z Morphol Anthropol 1924;24:157-189. 